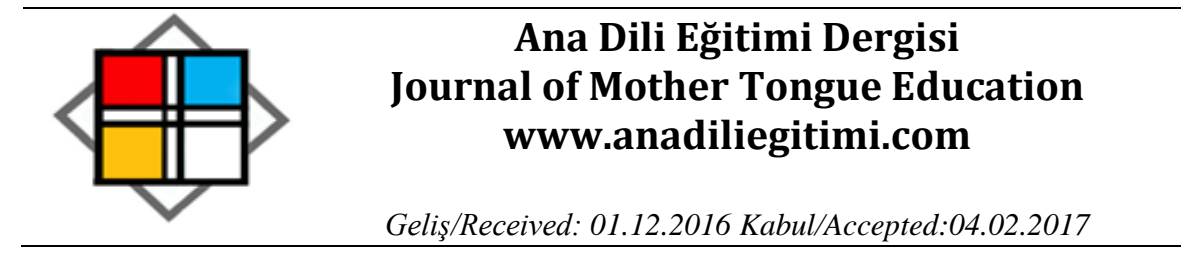

\title{
Yabancılara Türkçe Öğretiminde Filmlerin Kullanımı (Selvi Boylum Al Yazmalım Filmi Örneği)*
}

\author{
Adem işCAN** \\ Mahmut DELEN***
}

Öz

Yabancı dillerin öğretimi alanında kullanılan filmlerin, hedef dilin kültürünü öğrencilere öğretmedeki etkisi dünya çapında bilinmektedir. Kültür öğretiminin, dili öğrencilerin ilgisine açacağı düşünüldüğünde çalışmanın Türkçenin yabancı dil olarak öğretimi alanındaki önemi anlaşılacaktır. Bu araştırmanın amacı, Türkçenin yabancı dil öğretiminde filmlerin kullanılmasının, öğrencilerin Türk kültürel unsurlarını fark etmesine ortam hazırlama durumunu ölçmektir. Araştırmada betimsel tarama yöntemi kullanılmıştır. Öğrencilerin sorulara verdiği yanıtlar, nitel araştırma yöntemlerinden birisi olan doküman incelemesi ile analiz edilmiştir. Veri toplama sürecinde, literatür taraması sonucu araştırmacının hazırlamış olduğu sorular öğrencilere yöneltilmiştir. Elde edilen veriler, üç uygulama sonucunda analiz edilmiştir. illk olarak her bir öğrencinin vermiş olduğu yanıtlar tasnif edilmiştir. Daha sonra her uygulama için verilen yanıtlar, Microsoft Office Excel 2013 programına aktarılmış, burada analize tabi tutulmuş ve son olarak da her bir soruya verilen cevaplar için ortaya çıkan sonuçlar yorumlanmıştır. Elde edilen veriler, öğretmen yönlendirmesi sonucunda Türk kültür ögelerinin, filmler kullanılarak, geleneksel olarak tabir edilen yöntemlerden çok daha verimli biçimde öğretilebildiğini göstermiştir. Filmlerin öğrenciler tarafından ilgi ile takip edilmesi, öğrenmedeki verimi arttırmış, görsel olarak sunulan kültürel unsurlar, kuru bilgiden çok daha öteye geçerek kalıcı hâle gelmiştir.

Anahtar Kelimeler: Yabancılara Türkçe öğretimi, dil, kültür, film.

\section{Using Films in Teaching Turkish to Foreigners}

\section{(The Example of the Film Selvi Boylum Al Yazmalım)}

\begin{abstract}
The effect of films which are used to teach the culture of the target language is known worldwide in the field of teaching foreign languages. As the teaching of the target language culture attracts the attention of students, this study intends to make a contribution in the field of teaching Turkish to foreigners. The purpose of this research is to measure how the use of films in teaching of Turkish as a foreign language creates the circumstances for students to become aware of the elements of the Turkish culture. Descriptive survey method was used in the study. The answers given by the students to the questions were analyzed using document review which is one of the qualitative research methods. In the data collection process, questions which were prepared by the researcher based on the review of literature were asked to the students. The obtained data were analyzed at the end of three applications. Afterwards, the answers given by individual
\end{abstract}

\footnotetext{
* Bu çalışma ikinci yazarın yüksek lisans tezinden üretilmiştir.

** Doç. Dr. Gaziosmanpaşa Üniversitesi Eğitim Fakültesi Türkçe Eğitimi ABD adem.iscan@gop.edu.tr

*** Milli Eğitim Bakanlığı, mahmuddelen@hotmail.com
} 
students were classified as the first step. Then the responses for each application were transferred to Microsoft Office excel 2013 through which they were analyzed, and, finally, the results for the answers given to each question were interpreted. The obtained data showed that under teacher's guidance cultural items can be taught more efficiently, using films rather than traditional methods. Students' interest in the movies led to increased learning and the cultural elements presented visually became more permanent than ordinary textbook knowledge taught by teachers.

Keywords: Teaching Turkish to foreign students, language, culture, film.

\section{Giriş}

Küreselleşen dünyada yabancı dil öğrenmenin öneminin artması ve bu bağlamda yabancı dil öğrenmek isteyen insanların çoğalması, yabancı dil öğretme yöntemlerinin de gözden geçirilmesini sağlamıştır. Hem zamandan tasarruf etmek hem de daha pratik ve eğlenceli yöntemlerle dil öğrenmek isteyen insanlar için modern dünyanın imkânlarından da faydalanarak yeni yöntemler ortaya koymak, bir zorunluluk hâline gelmiştir. Yabancı dil öğretiminde tecrübeli olan milletler, dillerini öğretirken yeni ortaya çıkan yöntemleri de kullanarak günümüze uyum sağlamakta zorlanmamışlardır. Fakat Türkçenin yabancı dil olarak öğretiminde bu yöntemlerden faydalanıldığını ya da bu konularda yeterince çalışmalar yapıldığını söylemek güçtür. Bu nedenle Türkçenin yabancılara öğretiminde filmlerin kullanımını konu alan bu çalışmada öğrencilerin dikkatini çekmek ve kültürün dil öğretimi üzerindeki etkilerinden yararlanmak amacı ile "Selvi Boylum Al Yazmalım" gibi Türk sinema tarihinin en önemli filmlerinden biri kullanılarak örnek bir ders işleme yöntemi ortaya konmaya çalışılmıştır.

Film, işitsel-görsel bir sanat olarak -millî ruhu yansıtan düşünce ve duygularla şekillenentoplumun kültürel ve estetik imgelerini gerçekçi bir şekilde yansıtır. Film, gerçek yaşamı, popüler kültürü ve sanatı yansıtan bir aynadır.

Yabancı dil olarak dil öğretiminde filmlerin kullanılması ilgisiz gibi görünebilir ve hatta bazı öğretmenler filmleri kullanmayı fazlaca zaman israfı olarak görebilir. Ancak filmler, genellikle derslerin başında ya da sonunda küçük uyarıcılar olarak kullanılmaktadır. Buna ek olarak, sadece eğitsel değil de eğlenme amaçlı olduklarını düşündüklerinden öğretmenler filmleri düzgün öğrenme kaynağı olarak görmezler. Ancak, Stoller (1988:1)'e göre bazı öğretmenler ilk başlarda filmleri ve film ekipmanlarını kullanma konusundaki teknik zorluklar çekmiş, öte yandan filmlerin hedef dil seviyesinin gelişimine kültürel çalışmalara katkıda bulunduğunu düşünmektedirler. Filmlerin kullanımı, yabancı dil öğretiminde sınıflara farklıık, gerçeklik ve esneklik getirmiştir.

Champoux (1999)'a göre, günümüzde video kayıtlara erişmek ve sınıf içinde kullanmak kolaydır. Ayrıca, filmlerin üretim kaliteleri yüksektir, ekonomik bir seçimdir ve hem bilişsel hem de etkili deneyimler sunarlar. Bu yüzden 1970'den beri filmlerin ve videoların yabancı dil öğretiminde 
kullanımı giderek artmıştır. Stoller (1988:1) filmlerin sınıflarda kullanılan öğretim tekniklerini artırdığını aynı zamanda müfredata farklılık kazandırdığına dikkat çekmektedir. Champoux (1999), film sahnelerinin sundukları görsellik bakımından soyut tema ve kavramların öğretilmesini kolaylaştırdığını ileri sürmüştür. Ayrıca öğrenciler gerçekliği hissedebilmek için filmlerden faydalanabilirler. Allan (1985:48-65) filmlerin sunduğu gerçekçi örnekleri vurgulamaktadır. Sesle görüntüyü bir araya getirmek filmleri dil öğretimi için kapsamlı bir araç hâline getirir. Görsellik ayrıca öğrencilere yardımcı olur: Sözel mesajları destekleyerek ve dinlerken dikkatlerini artırarak öğrencilere yardımcı olmaktadır.

Yabancı dil öğretiminde, sadece öğretmen ve ders kitaplarının kullanıldığı durumlarda işitsel ve görsel araçlar büyük önem taşımaktadır. Türkçenin yabancı dil olarak öğretiminde, öğrencinin ilgisini çekecek, öğretim sürecinde etkinliklerin verimi, çağın şartlarına uygun işitsel ve görsel araçlarla yapılması gerekmektedir. Yabancılara Türkçe öğretiminde hedef kitlenin özelliklerini de dikkate alarak seçilecek filmler hem derse olan ilgiyi artıracak hem de dilin doğal kullanımının sınıf ortamına girmesiyle birlikte dil becerilerinin daha sağılıkı gelişmesin sağlanmış olacaktır (Yılmaz ve Diril, 2015).

Yabancılara Türkçe Öğretiminde filmlerin kullanımı her seviyede $(A 1, A 2, B 1, B 2, C 1, C 2)$ ve her türde (kelime öğretimi, okuma-anlama, dinleme, dil bilgisi vb.) en önemli etkiye sahip vazgeçilmez metottur (Gülseven, 2014).

Yabancı dil öğretiminde filmlerin kullanımı, Türkçenin yabancı dil olarak öğretilmesinde maalesef yeterince kullanılamamıştır. Bu da yapılan çalışmanın önemini ortaya koymaktadır.

Bu araştırmanın amacı; Türkçenin yabancı dil olarak öğretiminde filmlerin kullanılmasının, öğrencilerin Türk kültürel unsurlarını fark etmesine ortam hazırlama durumunu ölçmektir.

\section{Yöntem}

Araştırmada nitel araştırma yöntemlerinden biri olan doküman incelemesi kullanılmıştır. Doküman analizi deseni nitel araştırma kapsamında değerlendirilir. Bu yönüyle araştırma nitel bir çalışmadır. Doküman analizi deseni, araştırmanın amacına yönelik kaynaklara ulaşmada ve elde edilecek verilerin tespit edilmesinde kullanıı (Çepni, 2007). Doküman analizi, çalışılacak konular ile ilgili olarak yazılı ve basılı belgelerin analizini içerir (Yıldırım \& Şimşek, 2008).Bu çalışmada da Gaziosmanpaşa Üniversitesi TÖMER'de B1 seviyesinde olan Türkçeyi öğrenen yabancı öğrencilere Türk kültürünü öğretmek için yapılan bir dizi çalışmanın doküman analizleri yapılmıştır.

\section{Evren ve Örneklem}

Çalışmada, Gaziosmanpaşa Üniversitesi TÖMER bünyesinde Türkçe öğrenimi gören yabancı öğrencilere sorulan sorular kullanılmıştır. Değerlendirme çalışmalarına katılan öğrencilerin, 16 'sı (\% 
62) erkek, 10'u (\% 38) kız olup; bunların 18'i Türkmenistan, 2'si Afganistan, 2'si Suriye, 1'i Irak, 1'i Tunus, 1'i Gürcistan, 1'i Kongo uyrukludur.

\section{Veri Analizi}

09.11.2015 tarihinde öğretmen yönlendirmesi ile çalışmaya katılan 26 öğrenciye, bir hafta önce "Selvi Boylum Al Yazmalım" filminin İngilizce altyazılı hâli, dışarıdan hiçbir müdahale olmaksızın izletilmiştir. Aşağıda tablolarda "birinci uygulama" şeklinde belirtilmiş olan değerlendirme kısmı, öğrencilerin yardım almadan film içinde tespit ettiği Türk kültürel unsurlarından oluşmaktadır. "ikinci uygulama" kısmı ise, filmi kültürel unsurlar hususunda dikkat çekeceği yerlerde durdurarak izletmesi sonucunda, öğrencilerin gördüğü Türk kültürel unsurlarından oluşmaktadır.

Çalışmanın kalıcılığının ölçülmesi için çalışmanın tamamlanmasından bir ay sonra, aynı 26 öğrenci ile tüm ipuçları kaldırılarak, öğretmen yardımı olmadan son bir uygulama yapılmıştır. Son uygulamada çıkan sonuçlar ise "üçüncü uygulama" adı altında değerlendirilmiştir. Veriler, her öğrencinin kâğıdı incelenip tasnif edilerek çözümlenmiştir.

\section{Bulgular ve Yorum}

Bu bölümde, öğrencilerin sorulara verdiği cevaplar, çalışmanın amaçları bağlamında değerlendirilecektir. Cevapların değerlendirilmesinden sonra ise bu çalışmanın, yabancılara Türkçe öğretimi konusunda yapılmış çalışmalar ile benzerlik ve farklılıklar yönünden karşılaştırmalar yapılacaktır.

SORU 1: Filmde gördüğ̈̈nüz evlilik öncesi Türk kültürel unsurları nelerdir?

1. Uygulama: En yüksek oran ile (\% 46) şerbet içme ögesinin fark edilmiş olması, değişik renkte bir içeceğin filmde sunulmasının, öğrenciler için daha dikkat çekici olarak algılandığı düşünülebilir. Çiftlerin flört etmeyişinin fark edilmesi, \% 42'i oranında kalmıştır. Bunda çiftlerin birkaç kez ailelerinden gizli şekilde görüşmesinin, flört etmek biçiminde algılanmış olması muhtemeldir. Erkek tarafının kız evine görücü gelmesi de açık bir kültürel unsur olmasına karşın, öğrencilerin ancak \%42'si bunu görebilmiştir. Bu, erkek tarafının kız evine geliş sebebinin ne olduğunun öğrenciler tarafından anlaşılmamasının bir sonucu olabilir. Erkek tarafının kız evine tatlı getirmesi ise evlilik öncesi kültürel unsur tespitlerinde, birinci uygulama sonucunda öğrencilerin en az algıladığı kültürel öge olmuştur. Böyle olması, tatıının yenirken, bunun kız isteme olayının bir parçası olduğunun fark edilmeyişi ile alakalı olabilir.

2. Uygulama: Bu uygulamada, ilk uygulamada tespit edilen bütün Türk kültürel unsurlarının fark edilmesinde artış olduğu görülmektedir. Birinci uygulamada, diğerlerine göre daha az öğrencinin fark ettiği görücü gelinmesi sırasında erkek tarafının tatı getirmesi, \%26'dan, \%92'ye yükselmiştir. Bu 
artışın en büyük sebebinin, öğretmenin yönlendirmesi olduğu düşünülmektedir. Bu oran ile erkek tarafının tatlı getirmesi, ilk uygulamanın tersine en çok fark edilen kültürel öge hâline gelmiştir. Bunun sebebinin ise öğretmenin öğrencilere, bu görülenin, Türk kültürüne ait bir öge olduğunu sezdirmesidir, diye düşünülmektedir.

3. Uygulama: Üçüncü uygulamada şerbet içme kültürel unsuru (\% 73), birinci uygulamaya göre daha fazla, ikinci uygulamaya göre daha az öğrenci tarafından fark edilmiştir. Bunun sebebinin öğretmen yönlendirmesinin ortadan kalkması olduğu düşünülebilir. Çiftlerin flört etmemesi, ikinci uygulamada $\% 80$ oranında fark edilmişken, üçüncü uygulamada bu oran \%15'e düşmüştür. Bu düşüşün, son uygulamada öğrencilerin farklı sahnelerde daha önce öğretmenin yönlendirdiği bazı kültürel unsurların, flört olarak yanlış biçimde algıladığının etken olduğu söylenebilir. Erkek tarafının kız evine görücü gelmesi ve gelirken tatlı getirmesi kültürel unsurlarının oranlarında da ikinci uygulamaya göre düşüş olduğu gözlenmektedir. Bu düşüşün, öğretmen yönlendirmesinin olmayışına bağlı olduğu düşünülebilir.

SORU 2: Filmdeki dügün esnasında gördügünüz Türk kültürel unsurları nelerdir?

1. Uygulama: Düğünde silah kullanma kültürel unsurunun bu sorudaki diğer kültürel unsurlarından çok daha fazla öğrenci (\% 57) tarafından fark edildiği söylenebilir. Bundaki en büyük etkenin film içerisinde silahların üst üste patlayarak öğrencilerin dikkatini bu yöne çektiği düşünülmektedir. Gelinin bineceği aracın süslenmesinin ve gelin duvağına tel takılmasının fark edilmesi, düğün sahnelerinde hareketin çok olması sebebi ile sezilemeyerek az öğrenci tarafından (\% 23) fark edilmiş olduğu düşünülebilir.

2. Uygulama: Düğünde silah kullanmanın (\% 84) öğrenciler tarafından sorulduktan sonra, bunun bir kültürel unsur olduğunun öğretmen tarafından onaylanmasının, bu unsurun fark edilmesinde gözle görülür bir artışa ortam hazırladığı söylenebilir. Gelinin bineceği aracın süslenmesi (\% 76) ve duvağına tel takılması (\% 73) kültürel unsurlarının, birinci uygulamaya göre büyük oranda arttığı gözlemlenebilir. Bundaki etkenin ise öğretmenin filmdeki en hareketli sahnelerden biri olan düğün sahnesini durdurarak, öğrencilerin dikkatini sahnelere vermesini sağladığı düşünülmektedir. İlk uygulamada tespit edilememiş olan davul zurna çalınması (\% 84) ve mendil sallanması (\% 61) kültürel ögelerinin, bu uygulamada çoğunlukla tespit edilebilmiş olmasında da öğretmenin sahneleri durdurarak, öğrencilere "burada sizce bir Türk kültür unsuru olabilir mi?" şeklinde sorup ipucu vermesinin temel etken olduğu düşünülmektedir.

3. Uygulama: İkinci uygulamada öğrencilerin tespit ettiği beş kültürel unsurun "mendil sallanması" haricinde dördünün öğrenciler tarafından tespitinde azalma olduğu söylenebilir. Bu kültürel unsurların tespitinde görülen azalma, öğretmenin sahneleri durdurarak izletmeyişine 
bağlanabilir. Mendil sallanmasının hiçbir öğrenci tarafından son uygulamada kültürel unsur olarak görülememesi ise o sahnenin hızlı bir geçiş sahnesi oluşundan ya da dikkat çekici başka unsurların sahnede daha ön planda olmasından kaynaklanıyor olabilir.

\section{SORU 3: Filmde dikkatinizi çeken kadın-erkek ilişkileri konusundaki Türk kültürel ögeleri nelerdir?}

1. Uygulama: Illk uygulamada hiçbir kültürel unsurun (\% 30, \% 26, \% 30, \% 30, \% 7), öğrencilerin yarısı tarafından fark edilemediği görülmektedir. Bunda en önemli etkenin öğretmen yönlendirmesi olmadan, öğrencilerin gördüğü hangi şeyin, bir kültürel unsur olarak değerlendireceğini bilmemesi olduğu düşünülebilir.

2. Uygulama: Evlilik öncesi görüşülmemesinde (\% 33) öğretmen yardımı olmasına rağmen ilk uygulamaya göre küçük bir artış olduğu gözlemlenebilir. Bundaki etkenin ise "görüşmek" kelimesinin algılanmasında bir sorun olduğu düşünülebilir. Evlilik kararını kadının kendi adına alamaması olarak adlandırılan kültürel unsurun (\% 61) birinci uygulamadakinin aksine ikinci uygulamada öğrencilerin çoğunluğu tarafından fark edildiği söylenebilir. Bundaki etkenin film izlenirken öğretmenin öğrencilere dönüp "evliliğe kız kendisi karar verebiliyor mu?” diye sorması olduğu düşünülmektedir. Erkek ailesinin kızı görmeye gelmesi ise birinci uygulamada görülmesine rağmen ilginç şekilde ikinci uygulamada hiçbir öğrenci tarafından fark edilememiştir. Bunun sebebi olarak, öğretmenin söylediği bazı cümlelerin, öğrencileri bu konuda yanlış yönlendirdiği düşünülebilir. Kadınların erkeğin işine karışamaması kültürel unsurunun, öğrencilerin \% 84'ü tarafından fark edilmesi, öğretmenin kadının erkeğin işine karışması anında başına gelenlerin sebebini öğrencilere film izleme sırasında sormasına bağlanabilir. Kadınların erkeklerle konuşmaktan kaçınması (\% 3), ikinci uygulamada yalnızca iki öğrenci tarafından fark edilmiştir. Bundaki etkenin, öğretmenin bunun öğrenciler tarafından fark edileceğini düşünerek ipucu vermeyişi olduğu düşünülebilir.

3. Uygulama: Evlilik öncesi görüşülmemesinin (\% 7) öğrenciler tarafından tespitinin, üçüncü uygulamada daha da düştüğü söylenebilir. Bundaki etkenin daha önce de ifade edildiği gibi "görüşmek" kelimesinde öğrencilerin anlam karmaşası yaşadığı düşünülebilir. Evlilik kararını kadının kendi kendine alamayışı ikinci uygulamada öğrencilerin \% 61'i tarafından fark edilmiş iken bu oran üçüncü uygulamada \%3'e düşmüştür. Bu veri ışığında, ikinci uygulama ile üçüncü uygulama arasında geçen zamanın, öğrencilere verilen ipuçlarını unutturduğu düşünülebilir. Erkek ailesinin kızı görmeye gelmesi, ikinci uygulamada tespit edilemediği gibi üçüncü uygulamada da tespit edilememiştir. Bunda öğretmenin yönlendirmesinin, öğrencilerde yanlış bir kanaate sebep olduğu düşünülebilir. Kadınların erkeğin işine karışamaması, \%61'lik bir oran ile bu uygulamada en fazla tespit edilen kültürel unsur olmuştur. Bunda, öğretmenin ikinci uygulamada öğrencilere soru yönelterek, öğrencilerin bilgiyi kendilerinin bulmasını sağlayıp bilginin kalıcılığını arttırdığı düşünülebilir. 
SORU 4: Dilin kullanımı konusunda filmde duyduğunuz Türk kültürel unsurları nelerdir?

1. Uygulama: Eldeki veriler ışığında, dilin kullanımı konusunda öğrencilerin, öğretmenin verdiği ipuçları dışında herhangi bir kültürel unsuru fark edemediği düşünülmektedir. Öğretmenin değerlendirme formunda sorunun yanında parantez içinde verdiği örnekleri, tabloda belirtilen sayı ve oranda öğrenci görebilmiş; bundan başka bir kültürel unsura dikkat çekilmediği görülmüştür.

2. Uygulama: Veriler ışığında görüldüğü gibi, öğrencilerin ilk uygulamada yalnızca ipucu olarak verilen kültürel unsurları fark etmesine karşın ikinci uygulamada öğretmen yönlendirmesi sonucu, daha önce tespit edilebilen kültürel unsur sayısı 3 iken, ikinci uygulamada bunun 21 'e çıktığı düşünülmektedir. Araştırmadan elde edilen verilere göre, dilin kullanımı konusunda filmde görülen Türk kültürel unsurları, ikinci uygulamada öğretmenin yönlendirmesi ile birinci uygulamaya göre yüksek oranlarda arttığı ve fark edilen unsurların çeşitlendiği söylenebilir. Illk uygulamada tamamı yüzde ellinin altında kalan 3 kültürel unsurun fark edebilme oranının da bu uygulamada yüzde ellinin üzerine çıktığı gözlemlenmiştir.

3. Uygulama: Illk uygulamada 3 adet kültürel unsurun, ikinci uygulamada ise 21 adet kültürel unsurun gözlemlenmesine karşın, üçüncü uygulamada 11 adet kültürel unsur, öğrenciler tarafından tespit edilmiştir. Bu düşüşün sebepleri, öğretmen yönlendirmesinin ortadan kalkması ve ikinci uygulamanın üzerinden 1 aylık bir sürenin geçmiş olması olarak düşünülebilir. Dikkat çeken bir başka sonuç ise üçüncü uygulamada üzerinden zaman geçmiş olmasına rağmen öğrencilerin birinci uygulamada fark edebildiği üç kültürel unsurun tamamında, üçüncü uygulama sonucunda daha yüksek orada fark etmesidir. Bu veri ışığında, yapılan uygulamanın öğrencilerde kalıcı bir öğrenme oluşturduğu söylenebilir.

SORU 5: Filmde aile/evlat ilişkilerinde gördüğünüz Türk kültürel unsurlarını yazınız.

1. Uygulama: Öğrencilerin aile evlat ilişkilerini, kendi gayretleri ile sezmesi istendiğinde, tespit edilen kültürel ögelerin hiçbirinin \%30'un üzerine çıkamadığı söylenebilir. Bunda, film içinde aile ile evlat arasındaki ilişkinin çok vurgulu biçimde anlatılmamasının etken olduğu düşünülebilir.

2. Uygulama: Evlilik kararı aşamasında aile bireylerinin rolü, ilk uygulamada öğrencilerin $\% 11^{\prime} i$ tarafından fark edilmiş olmasına karşın öğretmenin yönlendirmelerde bulunduğu ikinci uygulamada \%3'e düşmüştür. Bundaki en önemli etkenin öğrencilerin öğretmene sorduğu sorular sonucunda yanlış anlaşılmaların gerçekleşmesi olduğu düşünülebilir. Gebe olduğunu söylemekten utanma ve evlatlıktan reddetme kültürel unsurlarının fark edilmesinde gözle görülür bir artış olduğu söylenebilir. Bundaki artış ise, öğretmenin filmi ilgili sahnelerde durdurarak, "burada ne oluyor?" diye sormasına bağlanabilir. Evladın annesinden korkması kültürel unsuru, birinci uygulamada fark edilememesine karşın ikinci uygulamadan öğrencilerin \%73'ü tarafından tespit edilmiştir. Burada ise öğretmenin 
öğrencilere "sizce her millette çocuklar, annelerinden bu kadar korkuyor mu?" diye sormasının etken olduğu düşünülebilir. Bela okumak eylemini, bu bağlamda bir kültürel unsur olarak değerlendiren öğrencinin öğretmen yönlendirmesi ile yapılan ikinci uygulamada bu kanaatinden vazgeçtiği görülmektedir.

3. Uygulama: Evlilik aşamasında aile bireylerinin rolü (\% 3), ikinci uygulama ile aynı oranda öğrenci tarafından fark edilmiştir. Gebe olduğunu söylemekten utanma (\% 30) ve evlatlıktan reddetme (\% 26) kültürel unsurlarının öğrenciler tarafından fark edilmesinin ikinci uygulamaya göre büyük oranda düştüğü gözlemlenmektedir. Üçüncü uygulamada öğretmenin söz konusu sahnelerde filmi durdurmamasının bu düşüşteki etken olduğu düşünülmektedir. Kız çocuğu üzerindeki egemenlik (\% 30) ise birinci ve ikinci uygulamada fark edilmesinden çok daha yüksek bir oranda fark edilmiştir. $\mathrm{Bu}$, öğrencilerin film üzerine düşünüp son uygulama gerçekleşene kadar arkadaşları ile filmdeki karakterlerin birbiri ile iletişimleri hakkında konuşmasına bağlanabilir.

Soru 6: Cinsiyetlerin, film içinde, Türk toplumunun gözünde nasıl değerlendirildiğini yazınız.

1. Uygulama: İlk uygulama sonucunda cinsiyetlerin Türk toplumu gözünde nasıl değerlendirildiği sorusunda, öğrencilerin yarısı tarafından fark edilmiş hiçbir kültürel öge yoktur. En yüksek oranda tespit edilmiş olan kültürel ögenin bu alanda kızın yüzüne kömür sürülmesi (\% 46) olduğu veriler ışığında söylenebilir. Bundaki temel sebebin, somut olarak kendini belli eden kültürel ögelerin daha kolay sezildiği dile getirilebilir.

2. Uygulama: Namus kavramının Türkler için kültürel bir unsur olduğunu düşünen öğrenciler, ilk uygulamada \%26 iken ikinci uygulamada bu oran \%3'e düşmüştür. Bu kavramın filmin genelinde geçiyor olması ve öğretmenin yönlendirme yapmak için bu konuda herhangi bir sahnede filmi durdurmaması, öğrencilerin bunun bir kültürel unsur olmadığını düşünmesine sebep olduğu düşünülebilir. Yine erkek kadın ilişkilerinin Türk kültürüne ait kültürel bir farklılığının olduğu, öğrencilerin \%15’i tarafından tespit edilerek, ilk uygulamadan daha düşük bir oranda farkındalığın oluştuğu söylenebilir. Bu bilgiler ışığında filmin geneline yayılan ve belirli sahnelerde dikkat çekmeyen bu gibi kültürel unsurların öğrenciler tarafından daha zor fark edildiği düşünülebilir.

3. Uygulama: Namus kavramını üçüncü uygulamada, ikinci uygulamada olduğu gibi öğrencilerin \%3'ü tarafından fark edilmiştir. Erkek kadın ilişkilerini kültürel bir unsur olarak algılayan öğrenciler, ikinci uygulama sonucu \%15 iken, üçüncü uygulamada bu oran \%26'ya yükselmiştir. Annenin kızının yüzüne kömür sürmesini Türk kültürüne ait bir unsur sayan öğrenciler, birinci uygulamaya göre daha fazla ancak ikinci uygulamaya göre daha az olarak göze çarpmaktadır. Üçüncü uygulama içinde değerlendirildiğinde diğer kültürel unsurlara göre, öğrencilerin bu kültürel unsuru çok daha kolay fark ettiği söylenebilir. Bu veri ışığında düşünüldüğünde, filmin bir sahnesinde somut 
olarak çabucak anlaşılabilen bir kültür ögesinin görülmesinin öğrencilerin kültür ögesini algılamasını kolaylaştırdığı söylenebilir.

Soru 7: Fiziksel özellikleri bakımından Türk kültürünün rolü hakkında filmden hareketle neler söyleyebilirsiniz?

1. Uygulama: İlk uygulamadaki veriler ışığında öğrencilerin, yarı yarıya bir oran (\% 50) ile sezebildiği hiçbir kültürel ögenin olmadığı söylenebilir. Filmde sahneler takip edilirken, genel bir soru olan bu sorunun rahat biçimde anlaşılamamasının bu konudaki etkenlerin başında geldiği düşünülebilir.

2. Uygulama: Kadınların örtünme şekli (\% 88) ve erkeklerin bıyık bırakmasının (\% 61) kültürel bir öge olarak anlaşılmasının, ikinci uygulamada gözle görülür biçimde arttığı söylenebilir. Ortaya çıkan bu bilgiye göre artışın sebebi düşünüldüğünde: Öğretmenin yönlendirme yaparken, "kadınlar dini inançları gereği mi örtünüyor, yoksa dini gereklerden farklı bir şey de olabilir mi?" ve "erkekler neden hep bıyıklı?” diye sorular sormasının etken olduğu düşünülebilir. Kadınların giyim şekillerini (\% 7) kültürel bir unsur olarak algılayan iki öğrenci ise kâğıtlarına bunu not ederek, birinci uygulamamadan başka bir kültürel unsuru da veriler arasına katmıştır.

3. Uygulama: Üçüncü uygulamada, önceki uygulamada öğrencilerin fark ettiği kültürel unsurların sayısında bir azalma olmamasına karşın, farkındalık oranlarında artışın olmaması dikkat çekmektedir. Bunun, öğretmen yönlendirmesinin ortadan kalkmasına bağlı olduğu söylenebilir.

\section{Soru 8: Komşuluk ilişkileri bakımından Türk kültürünün etkisi hakkında filmde neler fark ettiniz?}

1. Uygulama: İlk uygulamada komşuluk ilişkileri bakımından öğrencilerin yüksek oranlarla herhangi bir kültürel unsuru fark edemediği söylenebilir. Komşuluk ilişkisinin filmde gözlenmesinin geniş sahnelerle mümkün olduğundan ötürü bu farkındalığın istenen oranda olmadığı yorumu yapılabilir.

2. Uygulama: İlk uygulamada fark edilen kültürel unsurların tamamı, ikinci uygulamada kendine yer bulmuş; bunun yanında "bebeği olanı tebrik etmek" kültürel unsuru da üzerine eklenerek, öğrencilerin \%69'u tarafından fark edilmiştir. Öğretmen yönlendirmesinin devreye girmesinin ardından "komşuların zor durumda kalana sahip çıkası" kültürel unsuru haricinde, öğrencilerin fark etme oranının tamamında arttığı söylenebilir.

3. Uygulama: ỉkinci uygulamanın yapılmasının ardından uzun bir süre geçmesinin, üçüncü uygulamada kültürel unsurların fark edilmesini belirgin bir şekilde azalttığı düşünülmektedir. Bebeği olanı tebrik etmek (\% 69) kültürel unsurunun hiçbir öğrenci tarafından not edilmemiş oluşu göze çarpmaktadır. Komşuların zor durumda kalana sahip çıkması (\% 11) unsurunun fark edilmesindeki 
ufak bir artış olduğu, ancak kültürel unsurların tamamının fark edilme oranının üçüncü uygulamada azaldığı söylenebilir.

Soru 9: Türk mahalle kültürü hakkında filmde gördüğünüz özellikleri yazınız.

1. Uygulama: Birinci uygulama verileri ışı̆ıında: Türk mahalle kültürü hakkında yalnızca üç öge fark edilmiş; bunlardan da en yüksek oran (\% 46) ile fark edilen, belediye nikâhı ile dini nikâh farkının etkileri olmuştur. Filmin çarpıcı sahnelerinden birinde bir oyuncunun, önce dini nikâh yapılmasını önermesinin, bu farkındalıktaki etkisinin olduğu söylenebilir.

2. Uygulama: Duvara halı asılması kültürel unsuru, $\% 7^{\prime}$ lik bir oran ile fark edilirken, ikinci uygulamada bu \%42'ye; belediye nikâhı ve dini nikâh farkının etkileri \%46'lık bir oran ile fark edilirken \%84'e yükselmiştir. Ancak evlatlıktan reddedilince sığınılacak yerin bulunamaması ilk uygulama sonucu \%7'lik bir oran ile fark edilirken, ikinci uygulamada hiçbir öğrenci bu unsuru fark edememiştir. İkinci uygulamada, birinci uygulamada fark edilemeyen evde doğum yapmak unsuru, öğrencilerin \%73'ü tarafından kültürel unsur olarak nitelenmiştir.

3. Uygulama: Üçüncü uygulamada, ikinci uygulamada öğrenciler tarafından kültürel unsur olarak nitelendirilen bütün unsurlar kendine yer bulmuştur. Ancak tamamında öğrencilerin fark etme oranlarında düşüş olduğu söylenebilir. Bundaki etkenin, öğretmen yönlendirmesinin ortadan kalkması ve uygulamaların arasında uzun zaman olması olduğu düşünülebilir.

\section{Soru 10: Filmde gördüğünüz diğer Türk kültür unsurları nelerdir?}

1. Uygulama: Herhangi bir sınıflandırmaya tabi tutulamayacağı düşünülen diğer Türk kültürel unsurları sorulduğunda, eldeki veriler ışığında öğrencilerin bir kısmının, yalnızca kamyon üzerine yazı yazmayı (\% 38) tespit ettiği görülmektedir. Bu noktada somut olarak film içinde sahneler ile sürekli gösterilen bu kültürel ögenin diğerlerine nazaran çok daha bariz olarak tespit edilebileceği düşünülebilir.

2. Uygulama: Filmde görülen ve öğrenciler tarafından soru başlıklarında herhangi bir şekilde sınıflandırılamayan kültürel ögeler son soruda "diğer Türk kültürel unsurlar" olarak sorulmuş ve ilk uygulamanın sonunda yalnızca kamyonların üzerine yazı yazmak, öğrencilerin \%38'i tarafından tespit edilmiştir. ìkinci uygulamada ise bu sorudaki farkındalık artarak bulunan kültürel öge sayısı beşe çıkmış; ilk uygulamada bulunan kamyonların üzerine yazı yazmak ögesi ise bu kez öğrencilerin \%92'si tarafından tespit edilmiştir.

3. Uygulama: Diğer Türk kültürel unsurları hakkındaki üçüncü uygulamada ise birinci uygulamaya göre farkındalık artmış ancak ikinci uygulamaya göre azalmıştır. Bulunan kültürel öge sayısı ikinci uygulamaya göre azalarak üçe düşmüştür. 


\section{Tartışma, Sonuç ve Öneriler}

Filmlerin yabancı dil öğretiminde faydalı bir araç olduğu düşüncesi ile yaptığımız bu çalışma ile benzer öneride olan pek çok akademik çalışma mevcuttur. "Yabancı dil sınıflarında filmler çoğunlukla öğrencilerin dil ve kültürel yeterliklerini geliştirmek için kullanılır. Ayrıca dil ve kültürel yeterliklerin geliştirilmesi, film ve kültür analiz yeteneği ile birlikte yaratıcı ve eleştirel düşünme becerilerinin gelişimiyle bütünleştirilebilir" (Vázquez Vázquez, 2009). Bu çalışmada da filmlerin kültürel yeterlikleri geliştirdiği açıkça görülmüş; filmlerin, Türkçe öğretimi alanında kullanılması gereken bir öge olduğu ve bu bağlamda bir metodoloji ortaya koymanın önemi açıkça ortaya çıkmıştır.

Yabancı dil öğretiminde filmlerin kullanımı konusunda yalnızca Avrupa ve Amerika'daki örneklerden bahsetmek yeterli olmayacaktır. Batı'da sistematik bir biçimde metot olarak kullanılan yabancı dil öğretiminde filmlerin kullanımı, Uzakdoğu ülkelerinde de gereken öneme kavuşmaya başlamıştır. Wang (2009), "İngilizce Sınıflarda Filmlerin Kullanımı” başlıklı çalışmasında filmlerin yabancı dil öğretiminde kullanımıyla ilgili şu değerlendirmelerde bulunmuştur: "Bilgisayarların desteğiyle filmler (DVD, Mp3 vb.) Çin'de yabancı dil öğretiminde büyük rol oynamaktadır. Giderek artan sayıda öğrenci sadece sözel yönden değil dil edinim süreciyle de ilgilenmektedir. Günümüzde öğrenciler dil edinimini anlama ve bilgi edinme için giderek artan bir merak duymaktadır. Bu sebeple öğretmenler; görsel işitsel sınıfların nasıl daha etkili hâle getirileceği, öğrencilerin nasıl daha aktif katılımcı olmalarının sağlanabileceği, sınıflarda ne tür dinleme ve konuşma pratikleri yapılabileceği, öğrencilerin dil öğrenimde kendine güven duymasına nasıl yardım edilebileceği gibi bazı durumlarla karşıllaşmaktadır. Araştırmada öğrencilerin İngilizce öğreniminde özgüven oluşturmasından ve film kullanımına yönelik bazı kullanışlı ve pratik metotlardan bahsedilmiştir."

Filmlerin, yabancı dil öğretiminde öğrencilerin derse katılımı ve özgüven gelişimlerine katkıda bulunması hakkında yapılan başka çalışmalar da mevcuttur. Yapılan bu çalışmalarda, büyük oranda olumlu katkılar gözlenmiştir. Bahsettiğimiz bu çalışmalardan bir tanesinde ortaya çıkan sonuç, şu şekilde ifade edilmektedir: "Üniversite düzeyinde dil derslerinde film kullanımı üzerine yapılan bu araştırmada, öğrencilerin derse karşı açık ve istekli olduğu belirlenmiştir." (Sturm, 2012).

Çalışmadan önce yapılan literatür taramasında ortaya çıkan bir araştırma üzerine, Selvi Boylu Al Yazmalım filminin İngilizce altyazılı olan versiyonunun öğrencilere izletilmesine karar verilmiştir. Bahsedilen bu çalışmada, öğrencilerin altyazısız olarak filmi izlediğinde, pek çok noktada yardıma muhtaç hâle geldikleri şu biçimde ifade edilmiştir: "Yapılan araştırma ile altyazısız film izlemeyle, öğrencilerin dinleme becerilerini hangi ölçüde geliştirdiği bulunmaya çalışılış̧ır. Buradan hareketle öğrenci görüşleri alınmaya çalışılmıştır. Çalışma sonucunda öğrencilerin daha fazla zamana ve 
tavsiyelere ihtiyaç duydukları tespit edilmiştir. Ayrıca film kullanmak, öğrencilerin dinleme becerilerini geliştirici bir yol olduğu tespit edilmiştir. Öğrenciler, film izlerken sınıfta hem eğlendikleri hem de kendilerini rahat hissettikleri görülmüştür" (Safrani, 2015).

Yukarıda anılan çalışmalarda belirtildiği gibi yabancı dil öğretiminde filmlerin kullanımı, pek çok açıdan faydalar taşımaktadır. Başka bir araştırma (Seferoğlu, 2008) sonucunda da katılımcılar; uzun metrajlı film izlemeyle, hedef dile sahip kişilerin konuştuğu aksan, lehçe ve argo gibi çeşitli dil unsurları hakkında bilgi sahibi olduklarını, ayrıca, hedef dille ilgili söz dağarcığının zenginleştiğini ve hedef kültürü tanıdıklarını ifade etmiştir. Bu sonuçtan yola çıkarak, yabancı dil öğretiminde filmlerin kullanımının ne kadar olumlu sonuçlar ortaya çıkardığını ifade edebiliriz. Ortaya çıkan faydanın kalıcılığı ve öğreticinin katkısı ile ilişkisinin de ortaya koyulduğu bu çalışma, bize yabancılara Türkçe öğretimi konusunda filmlerin kullanımı ile geliştirilecek bir metodun önemini anlatmaktadır.

Araştırmada kullanılan Selvi Boylum Al Yazmalım filminde tespit edilebilecek Türk kültür unsurları, filmin içerdiği kültürel unsurlar ile sınırlıdır. Bu sebeple Türk kültür öğretiminde kullanılmak istenen filmler, öğrenci seviyesi ile uygunluğu bakımından irdelenmeli; öğretilmesi hedeflenen kültürel unsurların film içinde bulunup bulunmadığı iyice araştırılmalıdır.

Film sahnelerinde görülen kültürel unsurlardan en kapsamlı olanı olarak söyleyebileceğimiz, evlilik öncesi Türk kültür unsurlarının öğrenciler tarafından fark edilmesinde birtakım sorunlar görülmüştür. Öğrencilerin yarısından azı, filmde açık bir kültürel unsur olan "kız isteme" kültürel unsurunu fark edebilmiştir. Türk kültürü içinde önemli bir yere sahip olan kı istemenin, filmde gösterilmesine rağmen fark edilemeyişi üzerinde düşünüldüğünde: Filmi seyredenlerin, kız evine gelen topluluğun, ailesinden kızı istemek üzere geldiğini anlamaması olarak düşünülebilir. Ayrıca kız isteme sırasında tatı getirme kültürel unsurunun fark edilmesi de öğretmen yönlendirmesi sonucunda büyük bir oranda artmıştır. Bu iki verinin bize gösterdiği, öğretmenin kültürel ögenin ne olduğunu, sahne canlandığı sırada sorular sorarak öğrenciye keşfetme imkânı sunması gerekliliğidir.

Selvi Boylum Al Yazmalım filmi, Türk kültüründe zengin olan evlilik ve aile kültürünün pek çok unsurunu barındırmaktadır. Ayrıca bir Türk düğünün de canlandırıldığı filmde düğünlere ait kültürel unsurları öğretme imkânı da bulunmuştur. Düğün esnasında öğrencilerin en kolay biçimde fark ettiği kültürel öge silah atmak olmuştur. Bunda, film yönetmeninin, silah atma sahnelerini üst üste ve çarpıcı biçimde sunmasının en büyük etken olduğu düşünülebilir. Filmdeki düğün sahnelerinin hızı geçişlerle sunulmuş olması, öğrencilerin dikkatini kültürel ögelere vermesini azaltmış olduğu düşünülmektedir. Bunun önüne geçmek için öğretmenin, bu tip sahnelerde durdurarak; öğrencilerin kültürel öge algılamasını kolaylaştıracak sorular ile yönlendirme yapması yerinde olacaktır. 
Araştırmada da uygulanan bu yöntemin faydalı olduğu ve öğrencilerin kültürel öge farkındalığının ancak bu şekilde arttığı araştırma verileri ışığında söylenebilir.

Kadın erkek ilişkileri konusunda öğrencilerin filmde seyrettiği sahneleri idrak etmede zorlandığı söylenebilir. Bundaki etken düşünüldüğünde, kadın erkek ilişkileri gibi genel bir ifadenin, öğrencilerin kültürel unsurları kavramasında, olumsuz bir etki oluşturduğu düşünülebilir. Kadın erkek ilişkilerindeki kültürel unsurların fark edilmesinde istenen seviyede öğrenmenin gerçekleştiği tek unsur, kadının erkek işine karışmaması olmuştur. Bundaki etkenin, öğretmenin öğrencilerin keşfederek bulması için sorduğu isabetli bir sorunun, öğrenciler tarafından olumlu bir karşılık görmesi olduğu söylenebilir. Son uygulamada hiçbir hatırlatma yapılmadan iyi bir oranla bu ögenin fark edilmiş olması da buna dayanak olarak gösterilebilir.

Dilin kullanımı konusunda öğrencilerin kültürel unsurları fark etmesinde elde edilen veriler, nasıl bir yol izlenmesi gerektiğini ortaya koymuştur. Deyim, atasözü gibi kültürel unsurların öğrenciler tarafından sezilmesi, öğretmen yardımı olmadan son derece zor olduğu söylenebilir. Filmin sahneleri akıp giderken dilsel kültürel ögeler, öğrenciler tarafından kolaylıkla sezilememektedir. Öğretmenin, yazılı olarak öğrencilere uygulama sırasında doldurmasını istediği kâğıtlarda ipucu olarak verilen birkaç deyim ve atasözü, üç uygulamada da fark edilme konusunda kendine yer bulabilmiştir. Bu, yazılı olarak verilen atasözü, deyim, kalıp söz gibi dilsel kültürel unsurların kalııı bilginin yerleşmesine önemli katkıda bulunduğu yargısına ulaşmamızı sağlayabilir.

Aile ile evlat arasındaki ilişkilerden film içinde görülen Türk Kültür unsurlarının fark edilmesi konusunda istenen verim, öğretmen yönlendirmesi olmaksızın sağlanamamıştır. Öğretmen yönlendirmesi ve öğrencilere, bilginin fark edilmesine yönelik sorulan sorular uygulamaya eklendiğinde öğrencilerin kültürel farkındalığının arttığı söylenebilir.

Cinsiyetlerin Türk kültürü içinde kültürel öge olarak nitelendirilen kısmının öğrencilere öğretilmesi için araştırma kapsamında eldeki veriler ışığında birtakım bilgilere ulaşılmıştır. Buna göre, cinsiyetlerin Türk kültürü içindeki rolü, öğrenciler tarafından en kolay biçimde somut olduğu zaman anlaşılabilmektedir. Örneğin, gelinlik çağdaki kızın yüzüne kömür sürülmesi, filmde açık bir sahne olarak görüldüğü için fark edilmesinin daha kolay olduğu düşünülebilir. Ancak "namus" gibi filmin geneline yayılmış kavramların fark edilmesinin öğrenciler için zor olduğu düşünülebilir. Somut ve açık bir şekilde görülebilen kültürel ögelerin öğretimi için, öğretmenin bahsedilen sahnelerde filmi durdurarak, öğrencilerin hedeflenen ögeyi keşfetmesi için sorular sorduğunda olumlu sonuçlar alındığı rahatlıkla söylenebilir.

Fiziksel özelliklerin Türk kültürü bakımından hangi ögeler ile kendini gösterdiğinin öğretilmesi konusunda, öğretmen yönlendirmesinin olumlu etkileri elde edilen veriler ışığında görülmüştür. 
Örneğin, erkeklerin bıyık bırakmasının fiziksel özellikler bakımından bir kültür öge olduğu söylenebilir. Bunun anlaşılması için, filmin tüm sahnelerinde görülen erkeklerin neredeyse hepsinin bıyıklı olması öğrencilerin bir kısmına yetmemiştir. Erkeklerin toplu halde oturdukları bir sahnede filmi durdurarak “sizce erkekler neden hep bıyıklı?” diye sormanın, öğrencinin, bunun bir kültürel öge olabileceğini düşünmesini sağlayabilir. Bu konuda öğrencilerin, bunun kültürel bir öge olduğunu fark etmesinden daha önemli olarak düşünülebilecek bir fayda daha vardır. Öğrenciler, bunun ayrımına vardıktan sonra, bu kültürel ögenin fiziksel özelliklerden kaynaklı bir kültürel öge olduğunu da kendisi fark etmektedir. Öğretmenin doğrudan doğruya kültürel ögenin ne olduğunu ve hangi bağlamda bir kültürel öge olduğunu anlatması durumunda bu faydaların ortadan kalkma intimali olduğu düşünülürse, öğrencilerin kendi keşfetmesi ile bulduğu kültürel ögelerin çok daha faydalı olduğu söylenebilir.

Türk komşuluk ilişkilerinin öğrenciler tarafından anlaşılması için yapılması gereken çalışmalar konusunda da araştırmanın verileri ışığında bazı öneriler ortaya çıkmışır. Komşuluk ilişkileri konusunda öğrencilerin mahalle kültürü ve komşuluk kültürü arasındaki farkın tam olarak ayrımında olmadığı düşünülebilir. Komşuluk ilişkileri bakımından öğrencilerin yardım almadan istenilen seviyede bir farkındalığı oluşturamadığı söylenebilir. Komşuluk ilişkisi olarak kültüre yabancı olanların, pek çok hareketi komşuluk olgusunun getirdiğini yardım olmaksızın anlayamadığı düşünülebilir.

Türk mahalle kültürünün öğretilmesinde de daha önce yapılan tespitlerin benzeri ortaya çıkmıştır. Bu alanda da öğretmen yönlendirmesinin son derece etkili olduğu söylenebilir. Ancak mahalle kültürünün öğretilmesi konusunda diğer kültürel unsurların öğretilmesinde yer alan öğretmen yönlendirmesinin çok daha önemli katkılar yaptığı düşünülebilir. Somut olarak görülen mahalle kültür ögeleri, öğretmen yönlendirmesi devreye girdiğinde çok daha yüksek oranlarla istenilen öğrenme sonuçlarını ortaya çıkarabilmektedir. Örneğin, evde doğum yapmanın bir mahalle kültür ögesi olduğu, öğretmen yönlendirmesi ve öğretmenin öğrencilerin bu konuda sorduğu sorulara cevap vermesi sayesinde çok yüksek orandaki öğrenci toplulukları tarafından fark edilebilmektedir.

Filmler ile Türk kültürü öğretilmek istendiğinde, öğrencilerin herhangi bir sınıflandırmaya tabi tutamadığı kültürel ögeler de olmaktadır. Bunların da öğretilme gerekliliği düşünüldüğünde, öğrencilere, sınıflandıramadığı bir kültürel öge olup olmadığı da sorulmalıdır. Bu soru araştırmada yöneltilmiş ve en çarpıcı sonuç olarak, filmde aktör ve aktrislerin de sunum yaparcasına vurguladığı kamyon üzerine yazı yazmak kültürel ögesi kendine yer bulmuştur. Öğrencilerin öğretmen tarafından bu konuda yönlendirilmesinin ardından da öğrencilerin neredeyse tamamının bu kültürel ögeyi fark ettiği görülmüştür. 
Kaynaklar

Allan, M. (1985). Teaching English with video. London: Longman.

Champoux, J.E. (1999). Film as a teaching resource. Journal of Management Inquiry, 8(2), 206-217.

Çepni, S., (2007). Araştırma ve Proje Çalışmalarına Giriş (3.Baskı), Trabzon: Pegem A Yayıncılık,

Gülseven, Ü. (2014). Yabancılara Türkçeöğretiminde filmlerin önemi ve kullanımı. 3rd International Conference On Language And Literature "Turkish in Europa". Tirana/Albania, Proceedings Book, v. 2.

Safranj, J. (2015). Advancing listening comprehension through movies. procedia - social and behavioral sciences, 191(The Proceedings of 6th World Conference on educational Sciences), 169-173.

Seferoğlu, G. (2008). Using feature films in language classes. Educational studies, 34(1), 1-9.

Stoller, F. 1988. Films and Videotapes in the ESL/EFL Classroom. Paper presented at the annual meeting of the Teachers of English to speakers of other languages. http://www.eric.ed.gov/PDFS/ED299835.pdf (ErişimTarihi: 20.03.2015)

Sturm, J. L. (2012). Using film in the 12 classroom: a graduate course in film pedagogy. Foreign Language Annals, 45(2), 246-259.

VázquezVázquez, M. M. (2009). Teaching film or using film to learn language and culture? Diverse approaches to teaching film in foreign language centres. Lenguas Modernas, (34), 9-23.

Wang, Y. (2009). Using films in the multimedia English class. English Language Teaching, 2(1), 179-184.

Yılmaz, F.,\& Diril, A. (2015). Filmlerle yabancılara Türkçe öğretimi: Beyaz melek film örneği. Akademik Sosyal Araştırmalar Dergisi, 3(10), 223-240.

Yıldırım, A.,\& Şimşek, H (2008). Sosyal Bilimlerde Nitel Araştırma Yöntemleri (5. Baskı). Ankara: Seçkin Yayınları. 